\title{
Analisis Pengaruh Variabel Kualitas Layanan Terhadap Kepuasan Pelanggan Apotek Kimia Farma Jember
}

\section{(Analysis of the Effect of Variable Service Quality on Costumer Satisfaction in Kimia Farma Pharmacy Jember)}

\author{
Choirunnisa' Kurnia Safitri, Imam Suroso ${ }^{1}$, Ketut Indraningrat \\ Jurusan Manajemen, Fakultas Ekonomi, Universitas Jember (UNEJ) \\ Jln. Kalimantan 37, Jember 68121 \\ E-mail: choirunnisa.mgt@gmail.com
}

\begin{abstract}
Abstrak
Penelitian ini bertujuan untuk menganalisis pengaruh variabel kualitas layanan terhadap kepuasan pelanggan Apotek Kimia Farma Jember. Populasi dalam penelitian ini adalah pelanggan Apotek Kimia Farma Jember. Metode sampling yang digunakan adalah purposive sampling dengan jumlah responden sebanyak 108 orang. Variabel yang digunakan sebanyak 5 variabel. Lokasi penelitian di Apotek Kimia Farma Jember. Sumber data yang digunakan dalam penelitian ini berupa data primer yang merupakan jawaban dari kuesioner, sedangkan data sekunder pada penelitian ini berupa gambaran umum Apotek Kimia Farma, literature dari berbagai sumber, dan juga dari penelitian terdahulu. Alat analisis yang digunakan adalah Analisis Structural Equestion Modelling (SEM). Hasil penelitian menunjukkan bahwa : 1) Bukti fisik berpengaruh signifikan terhadap kepuasan pelanggan di Apotik Kimia Farma Jember; 2) Kehandalan berpengaruh signifikan terhadap kepuasan pelanggan di Apotik Kimia Farma Jember, dan; 3) Daya tanggap berpengaruh signifikan terhadap kepuasan pelanggan di Apotik Kimia Farma Jember; 4) Jaminan berpengaruh signifikan terhadap kepuasan pelanggan di Apotik Kimia Farma Jember; 5) Empati berpengaruh signifikan terhadap kepuasan pelanggan di Apotik Kimia Farma Jember.
\end{abstract}

Kata Kunci: kualitas layanan, kepuasan pelanggan, SEM, apotek kimia farma.

\section{Abstract}

This research aimed to analyze the effect of variable quality services to customer satisfaction in Kimia Farma Pharmacy Jember. The population in this research are customers of Kimia Farma Pharmacy Jember. Sampling method used is purposive sampling with the number of respondents 108 people. Variables used are 5 variables. This research located in Kimia Farma Pharmacy Jember. Primary data used in this research is the answer of the questionnaire, while secondary data in this study is a general overview of Kimia Farma, literature from many sources, and also from previous research. The analysis tool used Analysis Structural Equestion Modelling (SEM). The results showed that: 1) Physical evidence significantly effect on customer satisfaction in Kimia Farma Pharmacy Jember; 2) Reliability significantly effect on customer satisfaction in Kimia Farma Pharmacy Jember, and; 3) Responsiveness significantly effect on customer satisfaction in Kimia Farma Pharmacy Jember; 4) Assurance a significantly effect on customer satisfaction in Kimia Farma Pharmaciy Jember; 5) Empathy significantly effect on customer satisfaction in Kimia Farma Pharmacy Jember.

Keywords: quality service, costumer satisfaction, SEM, kimia farma pharmacy.

\section{Pendahuluan}

Menurut Keputusan Menteri Kesehatan Republik Indonesia No.1027/MENKES/SK/IX/2004, apotek adalah suatu tempat tertentu, tempat dilakukan pekerjaan kefarmasian dan penyaluran sediaan farmasi, perbekalan kesehatan lainnya kepada masyarakat. Kimia Farma merupakan perusahaan publik sekaligus Badan Usaha Milik Negara dan juga merupakan pioneer dalam industri kimia dan farmasi di Indonesia (http://www.kimiafarma.co.id/).

PT. Kimia Farma Apotek merupakan anak perusahaan yang dibentuk oleh Kimia Farma untuk mengelola apotek-apotek milik perusahaan yang ada, dalam upaya meningkatkan kontribusi penjualan untuk memperbesar penjualan konsolidasi PT. Kimia Farma Tbk. Hal ini sesuai dengan visi dan misi PT. Kimia Farma. Adapun visi PT. Kimia Farma adalah "Menjadi korporasi bidang kesehatan terintegrasi dan mampu menghasilkan pertumbuhan nilai yang berkesinambungan melalui konfigurasi dan koordinasi bisnis yang sinergis".

Semakin besarnya kegiatan bisnis di bidang Apotek, membuat tingkat kompetisi yang semakin ketat. Selain itu, rendahnya pangsa pasar yang disebabkan oleh banyaknya produsen yang terlibat di bisnis bidang apotek yang menyebabkan setiap perusahaan harus menempatkan orientasi pada kepuasan pelanggan melalui sebuah kualitas pelayanan yang baik.

Kualitas layanan adalah keseluruhan ciri serta sifat dari suatu produk atau pelayanan yang berpengaruh pada kemampuannya untuk memuaskan kebutuhan yang dinyatakan atau yang tersirat (Kotler, 1997:49). Layaknya sebuah perusahaan yang menawarkan pelayanan jasa, sebuah apotek Kimia Farma juga membutuhkan sebuah kualitas pelayanan yang baik. Dari hasil observasi, Kimia Farma telah banyak melakukan beberapa pelayanan di antaranya adalah,

1 Corresponding Author 
memiliki kelengkapan obat yang ditata layaknya supermarket, terdapat praktik dokter, memberikan diskon sebesar $5 \%$ apabila pelayanan resep dokter dilayani lebih dari 15menit, selain itu layanan pada apotik Kimia Farma juga dibuka hingga 24 jam.

Kepuasan pelanggan adalah perasaan senang atau kecewa seseorang yang berasal dari perbandingan kinerja atau hasil suatu produk dengan harapan-harapannya (Kotler, 2000:52). Model yang banyak dipakai untuk mengukur kepuasan pelanggan adalah model SERVQUAL (Service Quality) yang dikembangkan oleh Parasuraman et.al., dengan cara membuat penilaian kepuasan pelanggan yang mengutamakan aspek pelayanan. Analisis kepuasan pelanggan dilakukan pada lima dimensi kualitas layanan, yakni 1) tangibles, 2) reliability, 3) responsiveness, 4) assurance, dan 5) emphaty (Tjiptono, 2011:329). Selain itu Kimia Farma telah meraih beberapa penghargaan diantaranya Top Brand Award kategori in Recognition of Outstanding Achievement in Building the Top Brand pada tahun 2010, Super Brand pada tahun 2011, Indonesia Brand Champions dalam acara Brand Aquity Champions Pharmacy pada tahun 2012. Penghargaanpenghargaan ini membuktikan bahwa Apotek Kimia Farma memiliki nama baik di mata masyarakat atau konsumen. Sehingga membuat Apotek Kimia Farma memiliki tugas besar dalam menjaga nama baik ini yang salah satunya adalah memperbaiki kinerja pelayanan terhadap konsumen.

Seperti penelitian yang dilakukan oleh Eudora (2013), yang menjelaskan bahwa dimensi kualitas pelayanan meliputi bukti fisik, keandalan, daya tanggap, jaminan, dan empati berpengaruh terhadap kepuasan pelanggan. Konsumen yang puas berdampak terhadap minat untuk kembali ke apotek yang sama. Dampak tersebut menjadi alat promosi yang dapat berpengaruh sangat positif bagi usaha apotek.

Rumusan masalah dalam penelitian ini adalah : apakah bukti fisik, keandalan, daya tanggap, jaminan dan empati berpengaruh terhadap kepuasan pelanggan Apotek Kimia Farma Jember?

Tujuan penelitiannya adalah : untuk menguji pengaruh bukti fisik, keandalan, daya tanggap, jaminan dan empati terhadap kepuasan pelanggan Apotek Kimia Farma Jember.

\section{Metode}

\section{Rancangan Penelitian}

Penelitian ini menggunakan explanatory research, yaitu suatu penelitian yang dilakukan untuk menguji hipotesis-hipotesis yang ada.

\section{Jenis dan Sumber Data}

Jenis data yang digunakan adalah data kuantitatif. Dalam penelitian ini, jenis dan sumber data yang digunakan adalah data primer dan data sekunder. Data primer pada penelitian ini berupa jawaban dari kuesioner yang berisi tentang pernyataan responden terhadap variabel bukti fisik, kehandalan, daya tanggap, jaminan, empati, dan kepuasan pelanggan. Data sekunder pada penelitian ini berupa gambaran umum Apotek Kimia Farma, literature dari berbagai sumber, dan juga dari penelitian terdahulu. Skala pengukuran variabel dalam penelitian ini adalah dengan menggunakan skala likert 5 titik.

\section{Populasi dan Sampel}

Populasi dalam penelitin ini adalah seluruh pelanggan Apotek Kimia Farma .Jumlah sampel adalah sama dengan jumlah indikator dikalikan 5 sampai dengan 10. Maka jumlah sampel pada penelitian ini ditetapkan 18 indikator lalu dikalikan 6 $(18 \times 6=108)$. Metode pengambilan sampel dalam penelitian ini menggunakan sampel tanpa peluang (nonprobability sampling), dimana setiap anggota populasi tidak diketahui peluang atau kemungkinan terpilih sebagai sampel. Pengambilan sampel dilakukan dengan menggunakan metode purposive sampling. Adapun syarat yang ditentukan bagi responden adalah pelanggan Apotek Kimia Farma dengan syarat minimal tiga kali transaksi.

\section{Metode Analisis Data}

Alat analisis yang digunakan adalah Analisis Structural Equestion Modelling (SEM).

\section{Hasil dan Pembahasan}

\section{Hasil}

Uji Instrumen

Uji ini dilakukan dengan menggunakan analisis faktor konfirmatori (confirmatory factor analysis) pada masingmasing variabel dengan menggunakan program AMOS versi 5. Berdasarkan hasil uji validitas dan reliabilitas seperti menunjukkan bahwa nilai $\mathrm{t}$ (ditunjukkan oleh nilai C.R) untuk loading signifikansi 0,05 (nilai kritis $=1,96$ ), demikian juga nilai probabilitasnya lebih kecil dari $\alpha(0,05)$. Sehingga dapat disimpulkan bahwa semua variabel secara signifikan berhubungan dengan konstruk (semua indikator valid). Construct reliability sebesar 0,874, 0,886, 0,871, 0,884, 0,862 , dan 0,852 , berada diatas nilai yang direkomendasikan yakni minimal sebesar 0,60-0,70 dengan demikian semua indikator atau variabel adalah reliabel.

\section{Uji Asumsi Structural Equestion Modelling}

Setelah dilakukan uji validitas dan uji reliabilitas pada masing-masing variabel laten, maka dilakukan uji asumsi untuk melihat apakah persyaratan yang diperlukan dalam permodelan dapat dipenuhi. Persyaratan yang harus dipenuhi adalah asumsi multivariate normal, tidak adanya multikolinieritas atau singularitas dan outlier.

a. Uji Normalitas

Hasil pengujian normalitas atau assessment of normality (CR) (lampiran 4) memberikan nilai CR sebesar 1,451 terletak diantara $-1,96(-1,96 \leq \mathrm{CR} \leq 1,96 \quad(\alpha=0,05)$, sehingga dapat dikatakan bahwa data bersifat multivariate normal. Selain itu juga data bersifat univariat normal juga ditunjukkan oleh semua nilai critical ratio semua indikator diantara $-1,96(-1,96 \leq \mathrm{CR} \leq 1,96(\alpha=0,05)$.

b. Uji Multikolinieritas

Hasil pengujian memberikan nilai determinant of sample covariance matrix sebesar 27,365. Nilai ini jauh dari angka nol sehingga dapat disimpulkan bahwa data tidak terdapat masalah multikolineritas dan singularitas pada data yang dianalisis, sehingga data dapat dilanjutkan sebagai data dalam penelitian ini.

c. Uji Outliers

Hasil uji outliers pada penelitian dapat dilihat pada mahalnobis distance atau mahalnobis d-squared. Untuk menghitung nilai mahalnobis distance berdasarkan nilai Chi Square pada derajat bebas (jumlah variabel indikator 
dan variabel) pada tingkat signifikasi 0,05 adalah sebesar 35,17246 (berdasarkan Tabel distribusi $X^{2}$ df 23). Hasil uji outlier menunjukkan tidak ada satupun kasus yang memiliki nilai Mahalanobis distance lebih besar dari 35,17246, maka dapat disimpulkan tidak ada multivariate outlier dalam penelitian.

\section{Analisis Structural Equestion Modelling}

Selanjutnya variabel dilakukan uji kausalitas model dan uji signifikansi sesuai dengan tujuan penelitian yaitu menguji pengaruh bukti fisik, kehandalan, daya tanggap, jaminan, dan kepuasan terhadap kepuasan pelanggan di Apotek Kimia Farma Jember, serta didapatkan asumsi multivariate normal, tidak adanya multikolinieritas atau singularitas dan outlier, maka dapat dilanjutkan dengan uji kesesuaian model dan uji signifikasi kausalitas.

a. Uji Kesesuaian Model (Goodness-Of-Fit Test)

Berdasarkan hasil dapat diketahui bahwa dari delapan kriteria yang digunakan untuk menilai layak atau tidaknya suatu model, hanya ada satu kriteria yang dinyatakan marginal, tetapi secara keseluruhan dapat dikatakan bahwa kesesuaian model baik dan dapat diterima yang berarti ada kesesuaian antara model dengan data.

b. Uji Kausalitas

Dari model yang sesuai, maka dapat diinterpretasikan masing-masing koefisien jalur. Berdasarkan hasil kasualitas dapat disimpulkan rangkuman sebagai berikut.

\section{Tabel 1. Hasil Pengujian Kausalitas}

\begin{tabular}{|c|c|c|}
\hline No. & Hasil Pengujian Kasualitas & Keterangan \\
\hline 1 & $\begin{array}{l}\text { Bukti fisik berpengaruh signifikan } \\
\text { terhadap kepuasan pelanggan di } \\
\text { Apotek Kimia Farma Jember }\end{array}$ & $\begin{array}{l}\text { Signifikan } \\
\text { Diterima }\end{array}$ \\
\hline
\end{tabular}

2 Kehandalan berpengaruh signifikan Signifikan terhadap kepuasan pelanggan di Apotek Kimia Farma Jember

3 Daya tanggap berpengaruh signifikan Signifikan terhadap kepuasan pelanggan di Apotek Kimia Farma Jember

4 Jaminan berpengaruh signifikan Signifikan terhadap kepuasan pelanggan di Diterima Apotek Kimia Farma Jember

5 Empati berpengaruh signifikan Signifikan terhadap kepuasan pelanggan di Apotek Kimia Farma Jember

Sumber: Data diolah, 2015

\section{Pembahasan}

Hasil pengujian koefisien analisis structural equestion modelling, menunjukkan bahwa bukti fisik, kehandalan, daya tanggap, jaminan dan empati berpengaruh signifikan terhadap kepuasan pelanggan di Apotek Kimia Farma Jember. Berdasarkan hasil pengujian tersebut, maka hipotesis yang menyatakan, "ada pengaruh bukti fisik, kehandalan, daya tanggap, jaminan dan empati terhadap kepuasan pelanggan di Apotek Kimia Farma Jember" diterima. Hal ini mengindikasikan bahwa bukti fisik, kehandalan, daya tanggap, jaminan dan empati, memberikan pengaruh signifikan dalam meningkatkan kepuasan pelanggan di Apotek Kimia Farma Jember.
1. Pengaruh Bukti fisik Terhadap Kepuasan Pelanggan

Hasil penelitian ini menerima hipotesis pertama yaitu bukti fisik berpengaruh signifikan terhadap kepuasan pelanggan di Apotek Kimia Farma Jember. Hal ini juga mendukung hasil temuan yang dilakukan oleh Eudora dan Rihardimas (2013) yang menyatakan bahwa dimensi kualitas pelayanan meliputi bukti fisik berpengaruh terhadap kepuasan pelanggan. Bukti fisik sebagai keadaan fisik yang disediakan oleh penyedia jasa layanan untuk kepentingan pelanggannya agar pelanggan merasa nyaman dan dapat terlayani dengan baik adalah baik. Dengan kata lain adanya ruang tunggu yang disediakan oleh Apotek Kimia Farma bagi pelanggannya dengan menyediakan berbagai fasilitas seperti ruang tunggu, tempat duduk yang layak pakai dan fasilitas elektronik berupa televisi, adanya penataan interior ruangan yang didesain secara baik.

2. Pengaruh Kehandalan Terhadap Kepuasan Pelanggan Hasil penelitian menerima hipotesis kedua pada penelitian ini yang berarti kehandalan berpengaruh signifikan terhadap kepuasan pelanggan di Apotek Kimia Farma Jember. Hal ini juga mendukung hasil temuan yang dilakukan oleh Rihardimas (2013) yang menyatakan bahwa dimensi kualitas pelayanan meliputi dimensi kehandalan berpengaruh terhadap kepuasan pelanggan.

Dalam penelitian ini menunjukkan bahwa kehandalan merupakan dimensi yang memiliki pengaruh paling tinggi dibanding dimensi yang lain. Kehandalan sebagai kemampuan untuk menghasilkan kinerja pelayanan yang dijanjikan secara akurat dan pasti. Pelayanan yang ada harus tepat waktu dan dalam spesifikasi yang sama, tanpa kesalahan, serta pelayanan yang diberikan kapanpun adalah baik. Dengan artian lainnya bahwa adanya karyawan yang memiliki kehandalan didalam memberikan pelayanan dan informasi dengan segera kepada para pelanggannya dengan memberikan informasi yang jelas terhadap berbagai macam varian dan fungsi produk yang dibutuhkan oleh pelanggannya.

3. Pengaruh Daya Tanggap Terhadap Kepuasan Pelanggan Hasil penelitian ini menerima hipotesis ketiga pada penelitian ini yang berarti dimensi daya tanggap berpengaruh signifikan terhadap kepuasan pelanggan di Apotek Kimia Farma Jember. Hal ini juga mendukung hasil temuan yang dilakukan oleh Eudora dan Rihardimas (2013) yang menyatakan bahwa dimensi kualitas pelayanan meliputi daya tanggap berpengaruh terhadap kepuasan pelanggan.

Daya tanggap sebagai kemampuan para karyawan untuk membantu para pelanggan dan memberikan layanan dengan tanggap dapat tercermin pada kecepatan, ketepatan layanan yang diberikan kepada pelanggan. Dengan artian lainnya bahwa adanya respon yang baik yang diterima pelanggannya terkait pelayanan yang diberikan dalam hal merespon keluhan dari pelanggannya yang mengalami permasalahan atau kesalahan didalam proses pembelian suatu produk yang ada di Kimia Farma.

4. Pengaruh Jaminan Terhadap Kepuasan Pelanggan Hasil penelitian ini menerima hipotesis keempat yaitu jaminan berpengaruh signifikan terhadap kepuasan pelanggan di Apotek Kimia Farma Jember. Hal ini juga mendukung hasil temuan yang dilakukan oleh Eudora dan 
Rihardimas (2013) yang menyatakan bahwa dimensi kualitas pelayanan meliputi jaminan berpengaruh terhadap kepuasan pelanggan.

Jaminan berkaitan dengan kemampuan para karyawan dalam menanamkan kepercayaan kepada pelanggan serta pengetahuan dan sopan santun karyawan dalam memberikan layanan kepada konsumen adalah baik. Dengan artian lainnya bahwa adanya karyawan yang dapat memahami dan menyelesaikan permasalahan dari pelanggannya terhadap keinginan yang ingin dicapai oleh pelanggannya didalam pemenuhan kebutuhannya.

\section{Pengaruh Empati Terhadap Kepuasan Pelanggan}

Hasil penelitian ini menerima hipotesis kelima pada penelitian ini yaitu empati berpengaruh signifikan terhadap kepuasan pelanggan di Apotek Kimia Farma Jember. Hal ini juga mendukung hasil temuan yang dilakukan oleh Eudora (2013) yang menyatakan bahwa dimensi kualitas pelayanan meliputi empati berpengaruh terhada59p kepuasan pelanggan.

Empati merupakan kemudahan dalam melakukan hubungan, komunikasi yang baik, perhatian pribadi dan memahami kebutuhan pelanggan. Hal ini berhubungan dengan perhatian atau kepedulian karyawan terhadap pelanggannya. Dengan artian lainnya bahwa adanya karyawan atau petugas dari apotek kimia farma yang mudah bergaul dan berhubungan dengan pelanggannya dan dapat memberikan keakraban atau intimasi terhadap sebuah hubungan yang ada.

\section{Simpulan}

Berdasarkan hasil analisis yang telah dilakukan pada penelitian ini, dapat ditarik kesimpulan sebagai berikut;

a. Bukti fisik berpengaruh signifikan terhadap kepuasan pelanggan di Apotek Kimia Farma Jember. Hal ini membuktikan bahwa dengan adanya bukti fisik yang telah dapat memberikan kenyamanan pada pelanggannya akan meningkatkan kepuasan pelanggan;

b. Kehandalan berpengaruh signifikan terhadap kepuasan pelanggan di Apotek Kimia Farma Jember. Hal ini membuktikan bahwa dengan adanya kehandalan yang sesuai dengan harapan pelanggannya akan meningkatkan kepuasan pelanggannya;

c. Daya tanggap berpengaruh signifikan terhadap kepuasan pelanggan di Apotek Kimia Farma Jember. Hal ini membuktikan bahwa dengan adanya daya tanggap sebagai respon aktif didalam pelayanan akan meningkatkan kepuasan pelanggan;

d. Jaminan berpengaruh signifikan terhadap kepuasan pelanggan di Apotek Kimia Farma Jember. Hal ini membuktikan bahwa dengan adanya jaminan berkemampuan dan dapat dipercaya akan meningkatkan kepuasan pelanggan;

e. Empati berpengaruh signifikan terhadap kepuasan pelanggan di Apotek Kimia Farma Jember. Hal ini membuktikan bahwa dengan adanya empati yang memberikan kemudahan didalam melakukan sebuah interaksi akan meningkatkan kepuasan pelanggan.

\section{Ucapan Terima Kasih}

Penulis menyampaikan terima kasih kepada segenap responden yang telah berkenan memberikan data selama penelitian berlangsung, serta pihak Apotek Kimia Farma Jember.

\section{Referensi}

Dann, Dann. 2007. Competitive Marketing Strategy. Australia: Pearson Prentice Hall.

Eudora W. P, Immanuel. 2013. Pengaruh Dimensi Kualitas Layanan Terhadap Kepuasan Pelanggan Jasa Cipaganti Travel Tujuan JemberSurabaya. Sripsi. Jember: Universitas Jember.

Keputusan Menteri Kesehatan Republik Indonesia No.1027/ MENKES/SK/IX/2004 tentang Standart Pelayanan Kefarmasian

Kotler, Philip. 1997. Manajemen Pemasaran. Jakarta: PT Prenhallindo.

Kotler, Philip. 2000. Manajemen Pemasaran di Indonesia. Jakarta: Salemba Empat.

Maryanne M. Mowen, Hansen Don R. 2000. Akuntansi Manajemen, Edisi Kedua, terjemahan : A. Hermawan. Jakarta: Penerbit Erlangga.

Praviditasari, Revi. 2012. Pengaruh Kualitas Layanan Kemahasiswaan Terhadap Kepuasan Dan Loyalitas Mahasiswa Pada Fakultas Ekonomi Universitas Jember. Skripsi. Jember: Universitas Jember.

Rihardimas, Titis. 2013. Analisis Kualitas Layanan Yang Mempengaruhi Kepuasan Pelanggan Jasa Computer Berbasis Jaringan Di Kota Jember. Skripsi. Jember: Universitas Jember.

Tjiptono, Fandy. 2006. Pemasaran Jasa. Malang: Bayumedia Publishing.

Tjiptono, Fandy. 2011. Pemasaran Jasa. Sleman: Bayumedia Publishing.

Wijayanti, Hermin. 2012. Analisis Pengaruh Kualitas Layanan Terhadap Kepuasan Dan Loyalitas Nasabah Tabungan Britama Pada PT. Bank Rakyat Indonesia (Persero) Tbk Unit Randu Agung. Sripsi. Jember: Universitas Jember. 